\title{
The Notion 'Nature' as Emerging from N Kazantzakis Works and School Books of Life Sciences: A Case Study
}

\author{
Kalathaki Maria \\ Ph.D., Med. \\ School Advisor for Secondary Science Teachers of West Crete, Greece \\ E-mail: Kalathakimaria.edu@gmail.com
}

Received: March 15, 2016

Accepted: April 7, 2016

Published: April 15, 2016

doi:10.5296/gjes.v2i1.9518

URL: http://dx.doi.org/10.5296/gjes.v2i1.9518

\begin{abstract}
People struggled to explain the world around them and to build on the achievements of science and technology in order to improve the quality of life. The first questions raised for the properties and the beginnings of the external world, concerning all those perceived by human senses for the Nature. The ancient Greek spirit realized the Nature, organic or inorganic, as living, animated wholeness, as a universe. As Philosophy and Science developed, revealed the greatness of the creation of the world, cultivated the notion of the human superiority, with numerous cases of interpretation of the Nature based on the human creature. The concept of 'Nature' is intertwined with social choices and management practices. Environmental Ethics is education of values which allows the development of mechanisms that drive changes to attitudes and values, broaden and deepen the pedagogical dimension of theories of science and sociology.

In this paper is studied the issue of 'Nature' in a didactic research, through the philosophical approach of values of Educational of the Sustainable Development. The notion of Nature has significantly replaced by the term of 'Environment' attributing ecological, economic, scientific, aesthetic, existential, spiritual value. The research in this case study, carried out in the literature, with $\mathrm{N}$ Kazantzakis works and school books of Biology and Environmental Sciences, in order to clarify terms linked to the scientific and philosophical concept of 'Nature' and the 'nature' of the things. The educational intervention is a negotiation between literature and issues of the environmental science. This research materialized in the stage of preparing a seminar for science teachers on the teaching issues of 'Nature' and 'nature' of the things. In order to prepare the trainees, in a peer learning activity of $\mathrm{N}$ Kazantzakis works, to
\end{abstract}


extract those fragments are related to the term "Nature' from their point of view, and at the end, they co-form a theatrical lectern where they read the excerpts, in a structural and theatric way. 


\section{Introduction}

People struggled to explain the world around them and to build on the achievements of science and technology in order to improve the quality of life. The first questions raised for the properties and the beginnings of the external world, concerning all those perceived by human senses for the Nature. The ancient Greek spirit realized the Nature, organic or inorganic, as living, animated wholeness, as a universe. "The universe is not a collection of objects but a communion of subjects", as Thomas Berry writes in the seed of hope panel-Buddhism in action for peace. Thus, Nature vision by the Greeks of pre-Socratic era, reached the crossroad of two directions, of which one seemed to lead to a new religiousness, the other to the world-theory materialism. At the same time, Philosophy was distinguished from Science, in a strictest sense, and at the end of the 5th century BC, with Sophists, to the problems of the existence of the universe, of the Earth, with a language turning to a more logical concepts (Pelegrinis, 1999).

Undoubtedly, the major issues of pre-Socratic philosophy were found, much later, in the heart of the western thought, and the scientific seeds of pre-Socratic philosophy flourished centuries after, leading to great, undisputed findings and knowledge. As Philosophy and Science developed jointly and parallel, revealed the greatness of the creation of the world, cultivated the human superiority, with numerous cases of interpretation of the Nature based on the human creature. In nowadays, we maintain the concept of the existence of absolute moral and conceptual separation between human and other beings, between people and Nature. Also, the word environment, 'peri-vallon' in Greek language, that mainly used and has replaced the term 'Nature', has the meaning of people's surrounding, reveals precisely this arrogant human approach to nature, according to which, people is the center, the Archon of Nature, and the rest organisms around just exist to serve humans (Kaltsidopoulos, 2004).

The idea of 'Nature' has almost disappeared from the current discussions in Education, it has mainly replaced by the term, the notion and the approach of 'Environment'. Nature remains highly relevant to the philosophy and practice of Education, since tacit notions of human 'nature' and 'nature' of things and what constitutes underlying reality - the 'natural' order of things - necessarily orientates Education in fundamental ways. It is argued that underlying our various senses of nature is the idea of nature as the 'self-arising' whose intrinsic integrity, mystery and value implicitly condition our understanding of ourselves and of the reality in which we live (Bonnet, 2003).

The concept of 'Nature' is intertwined with social choices and management practices. In the framework of ESD, Nature has ecological, economic, scientific, aesthetic, existential, spiritual value (UNECE, 2005). In the last century, many institutions were established directly and indirectly to the Nature conservation through the protection and regulation of other issues, with ultimately beneficial effects. Initially, they concerned legislation on health and hygiene. The immediate protection actions of Nature were established after the 2nd World War, because of the emerging needs. They had the form of conventions, such as that of the prohibition of nuclear testing in some areas, the limitation of military flights in the Arctic, the confrontation of climate change and reduce of biodiversity, the elimination of poverty etc. 
For each of these global sustainable development challenges we need an ethical perspective based on wide understanding and basic agreement on key principles in order to guide our policies and approaches to dealing with them (Sarabhai, 2010). We need something, for example, like the 1948 Universal Declaration of Human Rights, a significant articulation of world-accepted basic values. Focusing on this 'nature-orientated' frame of mind offers the possibility of both contributing to the clarification of Sustainable Development (SD) as an idea, moving from he only policy to the frame of mind, identifying something which is of great educational importance in its own right, to our underlying relationship with nature which denies both ourselves and our relationship with the world as a whole (Bonnet, 2002).

Ethics and morals are expressions of a particular human tendency, the ethical, which is, mainly, observable in communication. It appears in three different kinds of situations: personal moral reactions, the norms for correct behavior and the ethical reflections. We discuss the diverse learning conditions of these situations and take specific notice of the risk of indoctrination. Environmental Ethics is Education of Values which allows the development of mechanisms that drive changes to attitudes and values, broaden and deepen the pedagogical dimension of theories of science and sociology. Ethics, as a set of rules and behaviors of human social coexistence with the rest creatures of the Earth, can be extended to the respect for nature, conscious of our responsibility for its protection and care. Certainly, the relationship of the contemporary human generation with the natural environment has influenced the formation of the moral values (Ohman \& Ostman, 2008). Consequently, the redefinition of the relationship between humans and environment demands further study of the moral point of view of the environmental problems and the needed attitudes of the future generations, constituting an imperative field of research and application of modern environmental ethics.

The following educational intervention is an experiential didactic approach of the concept of 'Nature', as value of the ESD, from philosophical and environmental approach, as it emerging from N Kazantzakis works. Conclusions guide to a theatrical lectern performance in the plenary session of the team. In this paper is presented a possible negotiation between literature and environmental issues, concerning the value of 'Nature'. The seminar was related to scientific concepts taught in secondary schools regarding the term of 'Nature'. The trainees, who participate in peer learning activities on $\mathrm{N}$ Kazantzakis works-fragments or wholes, read fragments referred to the issue "Nature' in a theatrical lectern, in a theatric way.

N Kazantzakis was born in Megalo Kastro (Heraklion), the capital of Ottoman-occupied Crete, in 1883 (written on N Kazantzakis Museum's website). He travelled a lot in the world and gathered images, ideas and experiences which he incorporated, mainly, into the subsequent reworking of the Odysey, also in all his works. He wrote books, film scripts and poetry, composed plays and drew up novels in French, compiled encyclopedias, dictionaries and schoolbooks, contributed to Greek and Russian newspapers and translated many books. He became famous during the last years of his life, with the works, among the others, Zorba the Greek, The Last Temptation of Christ, Freedom and Death, The Greek Passion- Christ is Re-crucified and his autobiography Report to Greco. In his prologue to Zorba book says the influences accepted by Homer, Buddha, Nietzsche, Bergson and Christ. Also Pantelis 
Prevelakis, the most authoritative N Kazantzakis interpreter, calls Nietzsche, Christ, Buddha, Lenin 'prophets' who conquered Kazantzakis. In the end, he even deny and Lenin, and his hero, pattern throughout his likeness, or "parallel", will be Odysseus. (Politis, 1980). In 1956, in Vienna, he was awarded the International Peace Award. In 1957 he lost the Nobel Prize by a single vote to the French writer Albert Camus. In 1956, Kazantzakis was awarded the International Peace Award, in Vienna. In his speech had said "Such a crucial moment. Amidst the progress of intellect and the moral level of the contemporary human, there is a great divergence, one of extreme danger. If we do not want to let the world sink into chaos, we must, as we have unchained the hidden forces in matter, to unchain love, the one imprisoned in every person's heart".

\section{Methodology}

The prepared material for the science teacher seminar of west Crete, Greece from the literature, in this case, with N Kazantzakis works, targeted to clarify the term of 'Nature' in the environmental science, as a possible negotiation of the didactic school objects. It was approached the issue of 'Nature' through the views of N. Kazantzakis, in the dipole of humans and God, humans and Life, humans and themselves. As Trautmann et al. (2003) concluded in a research through structured science experiments that followed by online peer review of their research reports, undergraduate students experienced science as a collaborative process of investigation, rather than a static collection of facts. According to participating faculty, students gained critical thinking and analysis skills and important understandings about the nature of scientific research. The significance of careful writing, data analysis, presentation, and review all were cited as aspects of the nature of science that students had learned through the peer review experience.

The meaning performance of the writer's Greek texts in a foreign language, than Greek, is very difficult, requires high-level use and understanding of both Greek and the foreign languages. This becomes more complicated because of the literary idiom of N. Kazantzakis. Some texts could read to more than one language, if the participants to the theatrical lectern are from many countries, demanding English to be the basic language, for the connection to their communication. As for the readers, who feel difficulties to attribute the exact meaning in the idiomatic language of $\mathrm{N}$ Kazantzakis or the Greek language which is not their mother tongue, it is useful to have the writer's words in their mind: "Before you start to read, have this in your mind, the words that I treat, accept them as matter, hard pits which enclose explosive power. Every word, in order to find what I want to say, you must allow it to make explosion inside you, and so will be liberated the imprisoned soul. Otherwise, there is no understanding" (Traveling). "The human heart is a skein of caterpillars - blew it, Jesus, become butterflies".

The research began with the visit to the website of N Kazantzakis Museum (Crete, Greece) to have the first sense and idea on his biography and works. Retrieved any valid and reliable information about N Kazantzakis life and work. After this, took place an extended reading of documents of European Union and UNESCO on ESD strategies, goals, values and priorities related to 'Nature' and 'Environment'. Following carried out a short inquiry of the word 
'Nature' and 'nature' in the school books of Biology and Environmental Sciences of Greek Lyceums. The read of some books of N Kazantzakis focused on those taught in schools and the discussing concepts of the issue of "Nature". Recorded the references to the terms 'Nature'-'Physis', 'Environment-Perivallon' and 'nature' of the things.

Navigation of many websites containing fragments from the writer's works, aspects of researchers and scholars on his works, also in ESD strategies, images and videos referred to the studied issue, contributed to the building up of the "large picture". The excerpts and quotes, were chosen to have deep naturalistic meaning and focusing on the philosophical, environmental and sustainable approach of "Nature". The retrieved material was prepared to be presented and discussed in a cyber-conference and a cyber-round table of the teacher seminar.

\section{Results and Discussion}

The issue of "Nature" penetrates all the school teachings from the different points of view of scientific and theoretical didactic cognitive objects. Our conceptions have extensive implications both on how we view the world and on how we view ourselves. "Look deep into Nature and then you will understand everything better" (Albert Einstein). Our views within this general sense of 'Nature', and the 'nature' of things, shape our conceptions of the reality and our sense of identity. The self-evident, where we position ourselves in this natural order, and what we see in our functions and responsibilities within this frame, are in part definitional of who we are (Bonnet, 2007). In schools, in the framework of ESD, we have to prepare the future scientists and politicians on certain key ethical values, each dealt with many ethical principles, in the context of specific challenges to make these agreements and undertake important future initiatives for the Nature, the Environment, and for themselves.

In the phase of the preparation of the material for the teacher seminar, it was approached the scientific issue of "Nature" as philosophic issue of existence and as ecological perspective of sustainable development, by stochastic inquiry. In this paper studied the concept of 'Nature' in school pedagogic, through the philosophical approach of values of ESD.

REFERENCES OF THE TERMS 'NATURE' AND 'ENVIRONMENT' ('PHYSIS' AND 'PERIVALLON' IN GREEK LANGUAGE) IN SCHOOL BOOKS. References for the terms 'Nature' 'Physis' in Greek Language and 'Environment' 'Perivallon'-means Surroundings, sought schoolbooks of Life Science taught in Greek General Lyceums. The researched school books were the 'Biology of General Education' of A, B and C classes, Biology C class of Natural Sciences orientation, as well as the Principles of Environmental Sciences (PES) of B class, lesson that last three years has become inactive, and Geology-Natural Resources Management (G-NRM) of A class that has to be chosen from a very small number of people in schools (ITYE, 2016).

It is impressive that the references to the term 'Environment' were much more than the references to 'Nature'. The Biology books had a very small number of both terms reports, opposed to PES and G-NRM. The book PES, in prologue and introduction chapter introduces the term of 'Nature' in relation to the social and environmental sciences ('Economic and 
social dimension of nature', 'The structure, organization and operation of the Environmental Science' 'Environmental Science, with its multidisciplinary content and inquiry methodologies, can connect human potential with nature, society and culture and thus develop creative quality intervention roles and co-responsibility in the environment'). It introduces the notion of Nature in regarding and in relation to the issues to be studied in the following chapters ('Organization and functioning of nature,' 'mode of communication with nature' 'Study of inter-related components and functions of Nature', unemployment, crime, poverty and malnutrition are in Nature ecological problems' 'To develop friendly lifestyles to the Nature', 'very complex, by their nature, environmental problems') etc.

In the Biology of A class there were several references to the complex terminology names as hypo-physis, apo-physis, dia-physis, pros-physis, epi-physis, sym-physis, kata-physis, ek-physis (out growth), adeno-hypo-physis, nervo-hypo-physis and no one to the notion 'Nature'.

With the meaning of physiology and characteristics, the term of nature used in Biology of A Class only once ('viscous mucus secretion glycoprotein nature's secreted by special cells') and none with the meaning of Nature'. In Biology of B class were 5 references, 3 were for Nature and the rest to nature. In the Biology of Natural Sciences orientation there were 6 references, all for Nature. In Biology C class of General Education there were 10, 6 of them were for Nature. Noteworthy was the reference to the nature of the ecosystem, in other words the nature of Nature ('Abiotic factors of an ecosystem are in continuous interaction with the biotic and define its nature and function').

Regarding the references of 'Environment' and 'environmental' terms, the books that had plenty were THE PES and THE G-NRM. The concept of the 'Environment' varies by chapter, as for example in the chapters of anthropology 'environment' is understood as stimuli space for humans, as surroundings inside and with the human is interaction. In ecology fields is listing as natural environment-with the sense of Nature. The word 'perivallontai' with the meaning of 'are surrounded', 'enclosed', usually referring to physical structures.

In particular, in the book PES, the number of references to the words 'environment' and environmental was extremely high, especially in the titles of contents where 'Nature' appears 7 times and 7 times the word 'environmental', also in the Prologue there were 7 references to the word 'environmental'. In the first 30 pages of PES counted more than 48 references to the 'environment' and 49 references to the 'environmental'. The number of reports in G-NRM, in the respective pages, were 40 for 'environment' and 13 for 'environmental', 7 references in Contents and one in the Prologue.

Generally observed that the number of reports increases depending on the chapter's theme, for example, in a page of a chapter of G-NRM the word 'environment' recorded 10 and on one page of PES there were 8 records of the word 'environmental' and 5 the word 'environment'. In Biology A, B and C classes of General Education, the total references to the word 'environment' are 25, 47 and 39 respectively, to the word 'environmental' 1, 2, 20 and to the word 'perivallontai' are 12,7 , and 3. 


\section{Macrothink}

Global Journal of Educational Studies

ISSN 2377-3936

2016, Vol. 2, No. 1

The theatrical lectern, which used to approach the value of 'Nature' as emerging from $\mathrm{N}$ Kazantzakis works and through the prism of ESD, is a participatory, experiential, didactic technique. It offered the possibility to approach philosophical issues of values linked to scientific didactic objects at schools also to accomplish on what sociologists of science have described how communities, not individuals, are the agents of scientific knowledge, that in order a "fact" to be produced, it must be judged and accepted by a larger collective of scientists (Carlsen et al, 2001).

THE 'NATURE' IN EDUCATION. The increasingly technologized approach to education that has emerged speaks at best of a severely impoverished view of nature and human nature and at worst of a pretty thorough disregard for them. Education, which is increasingly determined by standardized, measurable goals can hardly attend to the full development of individuals in its inherent fluidity and its many intangible nuances. Is Education, therefore, now in danger of losing its way, of becoming 'lost in space', Bonnet (2007) is wondering). As Life sciences expanded in many sectors of the human culture with many new bioethical issues linked to the future of human being, about the rest creatures on the planet, relevant to the future of nature, the human nature which are often controvertible and under question, moreover, in the dialectic between moral objectivism and moral relativism (Post, 2004).

WHAT IS 'NATURE'. What is 'nature'? Does not the term have diverse, and sometimes confusing, meanings? Indeed, for some, the very reality of nature is highly problematic. Nature continues relatively invisible in educational debate. It is (merely) a social or cultural 'construction' - perhaps now, for us, largely a product of the Romantic imagination - and therefore culturally relative, changing, transient. A chimera rather than a reality. Not to be taken too seriously - and certainly not something that can either root or guide our understanding (Bonnet, 2003). Huckle (2006) discusses about three 'Natures', the first that is in places where human beings have never been, the second where humans have lived in harmony and the third that humans created for their biotope.

As Life sciences are growing fast, there is a growing social concern with many arguments based on what is "natural" raising metaphysical questions about the justice-what is "given in nature" is a social construct as what may be presupposed in "human nature" (Post, 2004). With the developing human biotechnology, the ecological and health implications, the health risks and benefits of genetic modified food arises questions on the distinction between the "natural" and the "artificial", making the human species responsible for everything, or it greatly diminishes the "given" or contingent in nature (Sagoff in Post, 2004). "This vineyard, the earth, is ours, our own flesh and blood. We cultivate and prune it, we gather and tread its grapes, we drink its wine, we sing and weep; ideas and visions rise in our heads.".....

All of Kazantzakis's works contain an abundance of passages about rocks, soil, seeds, rain, air, rainbows, the sea, flowers, and flowering. Possibly no other modern writer has written as extensively about the cosmogonic energies of Nature, with as much poetic brilliance. Human life, he passionately declares, is rooted in the soil and its growth parallels the essential life of Nature (Venturini, 2015). For Kazantzakis, the central drama in Nature, the seeding, growth, fruition, is the supreme model for human development. "I condense into a lightning moment 
the seeding, sprouting, blossoming, fructifying, and the passing of every tree, animal, man, star, and god. All earth is a seed planted in the coils of my mind."

Agenda 2030 (UN, 2015) considers the prosperous and fulfilling lives are in harmony with Nature, in a world where wildlife and other living species are protected. It is envisages a world in which, from air to land, from rivers, lakes and aquifers to oceans and seas are sustainable. One in which humanity lives in harmony with nature and in which wildlife and other living species are protected. A world in which land, from rivers, lakes and aquifers to oceans and seas are sustainable.

WAY OF WATCH THE 'NATURE' THE NATURE OF 'NATURE'. Kazantzakis way of thinking is deeply inquiry, as in modern Didactic of Science and Pedagogic. He sets the questions and ponders on them with simple way, irritating to retrieve, from the mental background, of the most primitive to the most advanced ideas, helpings to think, combine, review and revise, to place opposite and judge them. As he says, "since we cannot change reality, let us change the eyes which see reality.... Zorbas sees everything everyday as if for the first time". This way of thinking is transformed in a very useful methodological process to teach students and trainees how to put and meditate questions on scientific and pedagogic issues. His way of thinking becomes more useful in issues have not a single unequivocal answer, such as the environmental and pedagogic, due to the multifactorial nature. Kazantzakis creates images, "pictures" of the subjects he studies, where the factors become actors, helping the reader, simultaneously, to build up, in his mind, his own aspects about his attitudes and behaviors, in a meta-cognitive view of the issue and the point of view of it, running quickly the line perceptions, views, opinions, beliefs, attitudes, values, ending to personality. "All my life, one of my greatest desires has been to travel-to see and touch unknown countries, to swim in unknown seas, to circle the globe, observing new lands, seas, people, and ideas with insatiable appetite, to see everything for the first time and for the last time, casting a slow, prolonged glance, then to close my eyes and feel the riches deposit themselves inside me calmly or stormily according to their pleasure, until time passes them at last through its fine sieve, straining the quintessence out of all the joys and sorrows" (Report to Greco).

In a letter to Galatea, N Kazantzakis wrote "If they could leave me in any place of the world, my first task would be to build a school... To teach them why they should become good teachers, good scientists, good and prolific fathers. To teach them how to read a poem, how they should watch the stars, the animals, the people, the ideas. If the school succeeds to get used the children to love the truth, beauty, ethics, the society and the nation, they progress and greatened. School is the root of all good and all bad. In teacher's hands is the future of the Tribe" (Andrikakis, 2007).

LIFE AND DEATH. N Kazantzakis wonderings about the terrestrial, spiritual and mental human life can promote rethinking and reviewing of attitudes and behaviors toward the life style and the orientation to the other beings of the close surrounding, to the national and global live communities and natural resources. He sets a definition of Life linking it directly to the death: "We come from a dark abyss, we end in a dark abyss, and the luminous interval, 
we call life". "We live alone, we die alone, the intermediate bright spot we call life" (Salvatores Dei). "As soon as we are born, we enter the return, simultaneously the beginning and turning back. Every moment we die. That's why many trumpeted. The goal of ephemeral life is immortality" (Odyssey). "Everyone has a circle of its own of things, trees, animals, people, ideas, and the circle each one, by himself, has the debt to save it. He, no one else. If he does not save it, he cannot be saved". "Look, one day I had gone to a little village. An old grandfather of ninety was busy planting an almond tree. 'What, grandfather!' I exclaimed. 'Planting an almond tree?' And he, bent as he was, turned around and said: 'My son, I carry on as if I should never die.' I replied: 'And I carry on as if I was going to die any minute.' Which of us was right?" (Zorbas). "We have only a single moment at our disposal. Let us transform that moment into eternity. No other form of immortality exists". "Where are we going? Do not ask! Ascend, descend. There is no beginning and no end. Only this present moment exists, full of bitterness, full of sweetness, and I rejoice in it all" (Salvatores Dei)

In the Prologue of Report to Greco, N Kazantzakis orchestrates his own ritual return to the Earth: "I collect my tools: sight, smell, touch, taste, hearing, brain. Night has fallen, the day's work is done. I return like a mole to my home, the ground. Not because I am tired and cannot work. I am not tired. But the sun is setting"..."I cast a final glance around me. To whom shall I say farewell? Mountains, the sea, the grape-laden climbing vine over my balcony? Virtue, transgressions? Refreshing water? Futile, futile! All these will descend with me into the soil"..."I extend my hand, I grasp the earth's latch to open the door and leave, but I hesitate on the threshold just a little while longer. My eyes, my ears, my bowels find it difficult, terribly difficult, to tear themselves away from the world's stones and grass. A man can say to himself: 'I am satiated, in peace; I have no more wants; I have fulfilled my duty and am ready to leave.' But the heart resists. Clutching the stones and the grass, it implores: 'Stay a little longer!"”.

THE 'NATURE' IN OUR HANDS. According to Earth Charter (2000), we urgently need a shared vision of basic values to form the basis of morality of the new world that is emerging. The respect and care for life in a sustainable community is to ensure Earth's bounty and beauty for present and future generations. As our society produces incredible amount of printed and audiovisual material, the literary works can provide the social and historical context of teaching in schools for research achievements of Sciences and many other research (Swann, translated by Raftopoulou A, 1999). In designing new school curricula in environmental science, which expected to guide the contemporary and future generations to progress, we have to take in consideration, at least the 'what we ought to do' when formulated our fate. We ought to hear N Kazantzakis voice "You have responsibility. You do not govern only your little insignificant existence. You're a roll where, for a moment, is played the fate of your kin (Salvatores Dei). The future of humanity and of our planet lies in our hands. It lies also in the hands of today's younger generation who will pass the torch to future generations. We have mapped the road to sustainable development; it will be for all of us to ensure that the journey is successful and its gains irreversible UN, 2015). If, therefore, moral respect corresponding to a first phase of environmental ethics dedicated to the conservation of endangered natural areas, the moral responsibility seems to represent a 'new 
period of ecology policy "more focused on the question of technology and the risks of (Larrere, 2007).

One goal of Agenda 2030 (UN, 2015) is to protect, restore and promote sustainable use of terrestrial ecosystems, sustainably manage forests, combat desertification, and halt and reverse land degradation and halt biodiversity loss According to Earth Charter (2000), it is critical for people to see themselves as citizens of one Earth, our common home, and to advocate for policies and practices at all levels that respect and care for the whole community of life and for future generations. N Kazantzakis, in the Saviors of God N Kazantzakis introduces a new wave of ecological concern setting the responsibility for earth caring and undertaking of environmental acts: "Every human has his own circle made up of things, trees, animals, humans, ideas - and he is duty-bound to save this circle. He, and no one else. If he does not save it, he cannot be saved"... "Love responsibility. Say: It is my duty, and mine alone, to save the earth. If it's not saved, then I am to blame." We need to foster intercultural understanding, tolerance, mutual respect and an ethic of global citizenship and shared responsibility, to reaffirm that planet Earth and its ecosystems are our common home and that "Mother Earth" is a common expression in a number of countries and regions. We acknowledge the natural and cultural diversity of the world and recognize that all cultures and civilizations can contribute to, and are crucial enablers of, sustainable development (UN, 2015).

\section{Epilogue}

There are numerous reasons why educators should be concerned with 'Nature' and its nature, yet the concept is rarely acknowledged or discussed today in educational circles. Yet, there are good reasons why we should rehabilitate the concept of 'Nature' into educational discourse. Not the least of these is the fact that education cannot avoid making assumptions about both nature and human nature and that these assumptions are fundamental to shaping it both conceptually and practically (Bonnet, 2003). On the one hand, for example, much of what we say and do in everyday life is implicitly informed by what is considered to be 'natural'. On the other hand, there are those longstanding dualisms in western thinking such as body/soul, nature/culture, natural/artificial, that place our understanding of nature and our relationship to it at the heart of articulating our underlying metaphysics.

\section{References}

Andrikakis, A. (2007). Nikos Kazantzakis Anniversary Special issue 50 years of his death. Patris newspaper, Publisher Mykoniatis SA, Heraklion Crete, Friday, October 26

Bonnet, M. (2002). Sustainability as a Frame of Mind-and How to Develop It. The Trumpeter, $18(1)$.

Bonnett, M. (2003). Retrieving Nature. Education for a Post-Humanist Age. Journal of Philosophy of Education Special Issue, 37(4).

Bonnet M (2007) Environmental ethics and the issue of Nature, University Notes Workshop 4-8 December, Graduate Program "Environmental Education" TEPAES, Aegean University, 
Rhodes

Carlsen W, Cunningham C, Trautmann N (2001) Peer Review by School Science Students: Its Role in Scientific Inquiry, Paper presented at the annual meeting of the National Association for Research in Science Teaching, St. Louis, MO, March 25-28

Earth Charter (2000). Earth Charter Initiative, http://www.earthcharter.org, retrieved 090316

Huckle J. (2006) Philosophical framework for ESD Understanding society and nature and sustainable development, University Notes Workshop 4-8 December, Graduate Program "Environmental Education" TEPAES, Aegean University, Rhodes

ITYE (2016) Institute of Computers Technology and Publications Diofandos, Greek Ministry of Research and Education, Institute of Educational Policy, http://ebooks.edu.gr/new/allcourses.php

Koltsidopoulos E. (2004), The word "Environment": an arrogant human approach to Nature, Journal for the Environmental Education, Issue 30, PEEKPE, Thessaloniki.

Kazantzakis N (1956) Speech of N Kazantzakis in the awarding of the Peace Prize in Vienna, June 28, 1956, available http://amis-kazantzakis.blogspot.gr/2008/06/blog-post_1263.html

Kazantzakis Museum (2015), N Kazantzakis, his life and works, available http://www.kazantzaki.gr/index.php?level=2\&lang=en

Larrere C (2007) Respect or responsibility? What ethics for the environment? University Notes Workshop 4-8 December, Graduate Program "Environmental Education" TEPAES, Aegean University, Rhodes

Ohman J \& Ostman L (2008) Clarifying the Ethical Tendency in Education for Sustainable Development Practice: A Wittgenstein-Inspired Approach, Canadian Journal of Environmental Education, 13 (1)

Pelegrinis T. (1999) Principles of Philosophy. School Book of C Class of Lyceums, Organization for Publishing School Books, Athens

Politis L (1980) History of Modern Greek Literature", Educational Foundation of the National Bank, printing press "Manutius" Athens p. 272

Post S (2004) Encyclopedia of Bioethics, 3rd ed, Macmillan Reference USA

Sarabhai V. Kartikeya (2010) Editor-in-Chief, An Ethical Framework for a Sustainable World, Journal of Education for Sustainable Development 4:2

"Seeds of Hope" exhibition: Visions of sustainability, steps toward change, http://www.sgi.org/in-focus/2010/seeds-of-hope.html

Trautmann N et al (2003) Learning Nature of Science Concepts through Online Peer Review of Student Research Reports, Paper presented at the annual meeting of the National Association for Research in Science Teaching, Philadelphia, PA, March 22-26, 2003 


\section{Macrothink}

Global Journal of Educational Studies

ISSN 2377-3936 2016, Vol. 2, No. 1

UN (2015) Transforming our world: the 2030 Agenda for Sustainable Development, Resolution adopted by the General Assembly on 25 September 2015, United Nations $\mathrm{A} / \mathrm{RES} / 70 / 1$

UNECE (2005) UNECE strategy for ESD which adopted at the high-level meeting of Environment and Education Ministers in Vilnius 2005, http://www.unece.org/fileadmin/DAM/env/documents/2005/cep/ac.13/cep.ac.13.2005.3.rev.1. e.pdf

Venturini F (2015) The Terrestrial Gospel of Nikos Kazantzakis - Will the Humans Be Saviors of the Earth? Introduction of book of Trise member Maskaleris Thanasis, Submitted by on Sun, 01/03/2015, TRISE: Transnational Institute of Social Ecology, http://trise.org/node/102

\section{Copyright Disclaimer}

Copyright for this article is retained by the author(s), with first publication rights granted to the journal.

This is an open-access article distributed under the terms and conditions of the Creative Commons Attribution license (http://creativecommons.org/licenses/by/3.0/). 